\title{
The pro-adhesive and pro-survival effects of glucocorticoid in human ovarian cancer cells
}

\author{
Lijuan Yin',*, Fang Fang2,, Xinglei Song1, Yan Wang1, Gaoxiang Huang1, Jie Su1, \\ Ning Hui ${ }^{2}$ and Jian Lu' ${ }^{1}$ \\ 1Department of Pathophysiology, The Second Military Medical University, Shanghai, China \\ 2Department of Obstetrics and Gynecology, Changhai Hospital, The Second Military Medical University, \\ Shanghai, China \\ *(Lijuan Yin and Fang Fang contributed equally to this work)
}

Correspondence should be addressed to Jian Lu or Ning Hui Email

lujian326@163.com or huning324@aliyun.com

\begin{abstract}
Cell adhesion to extracellular matrix (ECM) is controlled by multiple signaling molecules and intracellular pathways, and is pivotal for survival and growth of cells from most solid tumors. Our previous works demonstrated that dexamethasone (DEX) significantly enhances cell adhesion and cell resistance to chemotherapeutics by increasing the levels of integrin $\beta 1, \alpha 4$, and $\alpha 5$ in human ovarian cancer cells. However, it is unclear whether the components of ECM or other membrane molecules are also involved in the proadhesive effect of DEX in ovarian cancer cells. In this study, we demonstrated that the treatment of cells with DEX did not change the expression of collagens (I, III, and IV), laminin, CD44, and its principal ligand hyaluronan (HA), but significantly increased the levels of intracellular and secreted fibronectin (FN). Inhibiting the expression of FN with FN1 siRNA or blocking CD44, another FN receptor, with CD44 blocking antibody significantly attenuated the pro-adhesion of DEX, indicating that upregulation of FN mediates the pro-adhesive effect of DEX by its interaction with CD44 besides integrin $\beta 1$. Moreover, DEX significantly enhanced cell resistance to the chemotherapeutic agent paclitaxel (PTX) by activating PI-3K-Akt pathway. Finally, we found that DEX also significantly upregulated the expression of MUC1, a transmembrane glycoprotein. Inhibiting the expression of MUC1 with MUC1 siRNA significantly attenuated the DEX-induced effects of pro-adhesion, Akt-activation, and pro-survival. In conclusion, these results provide new data that upregulation of FN and MUC1 by DEX contributes to DEX-induced pro-adhesion and protects ovarian cancer cells from chemotherapy.
\end{abstract}

Journal of Molecular Endocrinology (2016) 57, 61-72

\section{Introduction}

Emerging lines of evidence showed that chronic stress has an impact on tumor growth and progression. An important stress hormone, glucocorticoids (GCs), can affect tumor biology not only by their immunosuppression and anti-inflammatory effects (Beck et al. 2009), but also by changing the tumor microenvironment as well as playing a direct role in regulating proliferation, differentiation, invasion, and apoptosis of tumor cells. Moreover, GCs are also widely used as comedication in cancer therapy of solid malignant tumors because of their beneficial effectiveness in treatment-related edema, inflammation, pain, and electrolyte imbalance (Rutz 2002, http://jme.endocrinology-journals.org DOI: 10.1530/JME-15-0142
C 2016 Society for Endocrinology Printed in Great Britain 
Rutz \& Herr 2004). GCs are also given before, during, and after chemotherapy of solid malignant tumors to reduce acute toxicity, particularly hyperemesis, and to protect normal tissue, e.g. bone marrow progenitor cells of cancer patients against the long-term effects of genotoxic drugs (Kriegler et al. 1994). More recent data indicate that GCs can inhibit apoptosis induced by chemotherapy not only in established cancer cell lines and tumor xenografts but also in the freshly isolated cells from surgical resections from tumors of various origins, including ovary, breast, prostate, pancreas, liver, colon, brain, cervix, bone, skin, and nervous system (Herr et al. 2003, Sui et al. 2006, Zhang et al. 2006a,b). The GC-induced pro-survival effects should be of important clinical relevance when they interfere with the effect of chemotherapeutics.

The effect of GC is mediated by GC receptor (GR), a member of the nuclear receptor family. As a liganddependent transcription factor, liganded GR regulates gene expression through either direct interaction with GC response elements (GRE) in the promoter region of target genes (Phuc Le et al. 2005, Baschant \& Tuckermann 2010) or an interference with other transcription factors to inhibit their transcriptional activity (Kassel \& Herrlich 2007, Baschant \& Tuckermann 2010). Increasing evidence in tumor models demonstrated that GC could enhance cancer cell resistance to unfavorable microenvironment and chemotherapeutics in epithelial (i.e., 'solid') tumors, which is very important for the progression of cancer (Herr et al. 2007), and should be of important clinical relevance when it interferes with the effect of chemotherapeutics. The pro-survival and antiapoptotic effects of GC are meditated by GR through regulating the expression of genes, such as inhibitors of apoptosis (CIAP2, XIAP, BCL-XL, and $B C L 2)$, mitogen-activated protein kinase phosphatase-1 (MKP1), as well as serum- and glucocorticoid-inducible kinase-1 (SGK1) (Kyriakis et al. 1994, Schmalzing et al. 1995, Price et al. 1996, Paul et al. 1997, Warny et al. 2000).

Cell adhesion to extracellular matrix (ECM) is pivotal for survival and growth of most of the solid cancer cells derived from epithelium, and is mediated by several cell surface adhesion molecules (such as integrin $\beta 1$ and CD44) and their ligands (ECM components, such as collagens, fibronectin, and laminin) (Ponta et al. 2003, Zaidel-Bar \& Geiger 2010). Binding of cell surface adhesion molecules with their ligands not only supports cell adhesion, but also brings cytoplasmic molecules together to form protein-rich focal complexes that activate focal adhesion kinase (FAK) and several intracellular signaling molecules and pathways, such as Rho GTPases, Ras GTPase, Src, and the PI-3KAkt pathway, which regulate cell proliferation, survival, spreading, and migration (Hynes 2002, Ponta et al. 2003, Zaidel-Bar et al. 2007, Zaidel-Bar \& Geiger 2010, WinogradKatz et al. 2014). The adhesion process is controlled by multiple signaling molecules and intracellular pathways. Our previous works demonstrated that treatment of human ovarian cancer cells with dexamethasone (DEX), a synthetic GC, significantly increases cellular adhesion to ECM and their resistance to apoptosis induced by cytotoxic drugs, cisplatin, and paclitaxel (Chen et al. 2010). Increasing protein levels of adhesion molecules, integrins $\beta 1, \alpha 4$, and $\alpha 5$ by DEX are partly involved in pro-adhesive effect of DEX and chemoresistance. It is well known that integrin $\beta 1$ subfamily plays a crucial role in regulating cell adhesion by interacting with ECM proteins, such as collagens, fibronectin (FN), and laminin (Hynes 2002, Zaidel-Bar et al. 2007, Zaidel-Bar \& Geiger 2010). However, it is unclear whether DEX also affects the expression of ECM components, the ligands of integrin $\beta 1$, or whether other membrane molecules besides integrin $\beta 1$ are involved in pro-adhesive effects of DEX in ovarian cancer cells.

In order to further explore the mechanism of proadhesive and pro-survival effects of DEX, we investigated the effect of DEX on the expression of components of ECM, cell adhesion glycoprotein CD44, and mucin antigen 1 (MUC1), a large transmembrane epithelial mucin glycoprotein. We found that DEX significantly upregulated the expression of FN and MUC1. Enhancing cell adhesion by DEX through increasing FN-receptor (FN-integrin $\beta 1$ and FN-CD44) interaction and MUC1 could activate Akt signaling, thereby enhancing the resistance of ovarian cancer cells to chemotherapeutic drugs.

\section{Materials and methods}

\section{Cell culture}

Human ovarian cancer cell line HO-8910 was established and kindly provided by Dr Xu Shenhua (Zhejiang Cancer Research Institute, Zhejiang Cancer Hospital, China) at passage number 26 (Mou et al. 1994). SKOV-3 cell line was obtained from the National Infrastructure of Cell Line Resource (Beijing, China) at passage number 30. The two cell lines were cultured in RPMI-1640 (Gibco) containing $10 \%(\mathrm{v} / \mathrm{v})$ newborn calf serum (NCS, PAA Laboratories $\mathrm{GmbH}$, Pasching, Austria), $100 \mathrm{U} / \mathrm{mL}$ penicillin, and $100 \mathrm{mg} / \mathrm{mL}$ streptomycin (Boguang Technology, Inc, China) at $37^{\circ} \mathrm{C}$ under a humidified atmosphere of air containing $5 \%(\mathrm{v} / \mathrm{v}) \mathrm{CO} 2$. Cells were grown to $\sim 70 \%$ confluence, and rinsed thrice with $1 \times \mathrm{PBS}$, then cultured in medium containing $5 \%(\mathrm{v} / \mathrm{v})$ dextran-coated charcoal

Published by Bioscientifica Ltd. 
(DCC)-treated NCS to avoid possible interference of serum steroids, and the cells were incubated with $10^{-7} \mathrm{~mol} \mathrm{~L}-1$ DEX (Sigma) for different periods of time. Control cells were incubated with ethanol vehicle $(<1 \%$ (v/v)).

\section{Real-time PCR}

Total RNA was extracted with the TRIzol reagent (Invitrogen). After reverse transcription (RT) (Takara Bio), the cDNA products were amplified using SYBR Green PCR Master Mix (TOYOBO, Japan) at an annealing temperature of $52^{\circ} \mathrm{C}$ (collagen I and laminin), $50^{\circ} \mathrm{C}$ (collagen III), $54^{\circ} \mathrm{C}$ (collagen IV), $60^{\circ} \mathrm{C}$ (FN1), or $58^{\circ} \mathrm{C}$ (MUC1 and GAPDH). The primers were 5'-AGAGTGGAGCAGTGGTTAC-3' (forward) and 5'-CTTGTAGTGGATGGTGACG-3' (reverse) for collagen I; 5'-CTCCAACTGCTCCACTC-3' (forward) and 5'-CCTCATCGTCATCCTCCT-3' (reverse) for collagen III; 5'-CACAGCCAGACCATTCAG-3' (forward) and 5'-GTTAATGATGCGTTTGCGAA-3' (reverse) for collagen IV; 5'-CGGTGGCTGTCAGTCAAAG-3' (forward) and 5'-AAACCTCGGCTTCCTCCATAA-3' (reverse) for FN1; 5'-CTCGCCTCCTTGATGAAC-3' (forward) and 5'-GACACCACCAGACCAATG-3' (reverse) for laminin; 5'-TCAGTGCCGCCGAAAGAAC-3' (forward) and 5'-GCTCATAGGATGGTAGGTATCCC-3' (reverse) for MUC1; 5'-CATGAGAAGTATGACAACAGCCT-3' (forward) and 5'-AGTCCTTCCACGATACCAAAGT-3' (reverse) for GAPDH.

\section{Western blot}

Total cell lysates were prepared with $1 \times$ SDS lysis buffer containing $10^{-4} \mathrm{~mol} \mathrm{~L}^{-1} \beta$-mercaptoethanol, and $2 \mathrm{mg} / \mathrm{mL}$
A

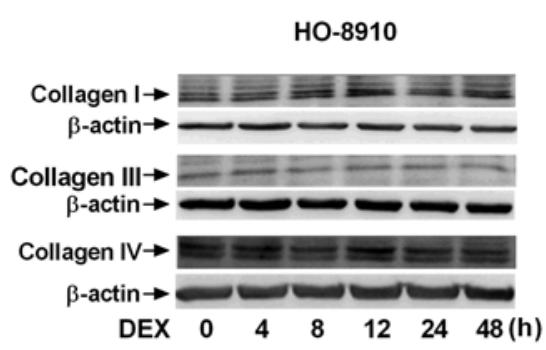

B
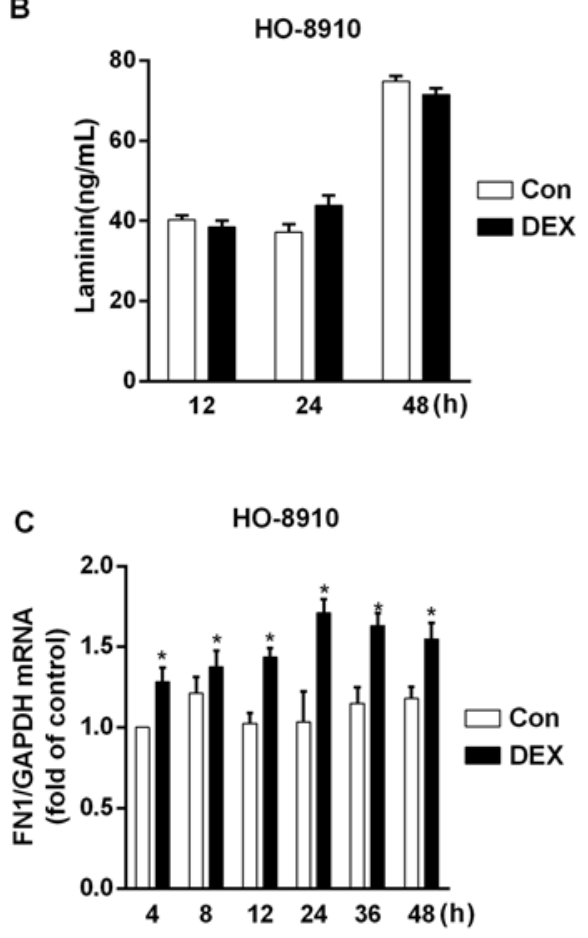

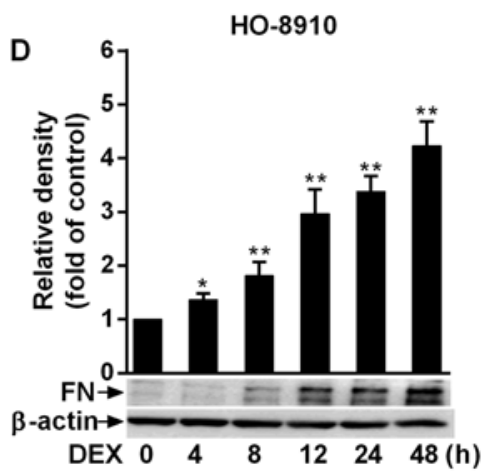

E

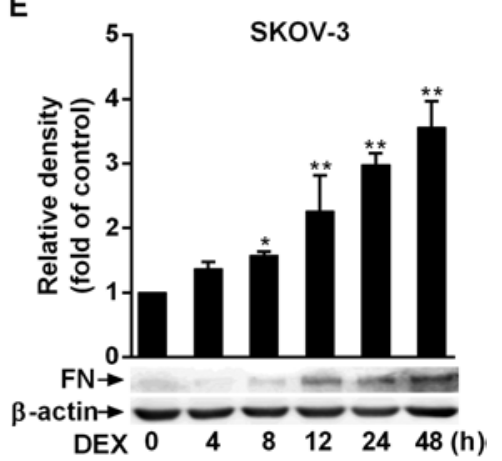

$\mathbf{F}$

\section{SKOV-3}

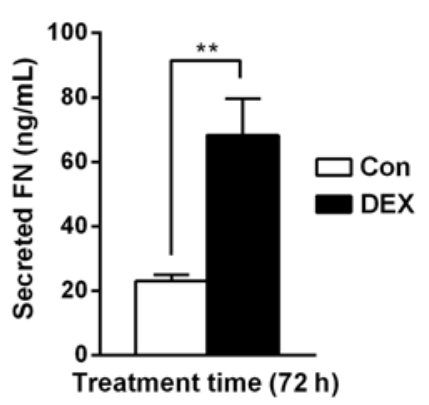

Figure 1

DEX upregulates the expression of $\mathrm{FN}$, but does not affect the expression of collagens and secretion of laminin in ovarian cancer cells. HO-8910 cells were treated with $10^{-7} \mathrm{~mol} \mathrm{~L}^{-1}$ DEX for the indicated times. The protein levels of collagen I, III, and IV were assessed by Western blot (A) and secreted protein of laminin was determined by ELISA (B) as described in Materials and methods. The expression of FN1 mRNA in HO-8910 cells treated with $10^{-7} \mathrm{~mol} \mathrm{~L}^{-1}$ DEX for the indicated times was assessed by Real-time PCR (C) normalized to GAPDH. Data shown are representative of at least three separate experiments. $\mathrm{FN}$ expression in $\mathrm{HO}-8910$ (D) and SKOV-3 cells (E) treated with $10^{-7} \mathrm{~mol} \mathrm{~L}^{-1}$ DEX for the indicated times were assessed by Western blot and $\beta$-actin was used as normalization control. Relative density for Western blot was analyzed by Image $1.40 \mathrm{~g}$ software and the results were expressed as fold of control and representative of at least three independent experiments. The secreted levels of FN in SKOV-3 cells treated with or without $10^{-7} \mathrm{~mol} \mathrm{~L}-1$ DEX for $72 \mathrm{~h}$ were determined by ELISA. The concentration of FN was calibrated from a dose-response curve based on reference standards. The experiments were performed in triplicate (F). ${ }^{*} P<0.05, * * P<0.01$ vs control. http://jme.endocrinology-journals.org DOI: 10.1530/JME-15-0142
(C) 2016 Society for Endocrinology Printed in Great Britain 
of each of the protease inhibitors leupeptin, aprotinin, and pepstatin. After electrophoresis, the proteins were transferred onto a nitrocellulose membrane, blocked with $5 \%(\mathrm{v} / \mathrm{v})$ nonfat milk in Tris-buffered saline Tween 20 (TBST), and immunoblotted overnight at $4^{\circ} \mathrm{C}$ with primary antibodies against human $\beta$-actin (A5441, Sigma, 1/10,000), MUC1 (ab109185, Abcam, 1/5000), FN (sc-6953), collagen I (sc-8784), III (sc-8781), and IV (sc-9302), AKT (sc-8312) and p-AKT (sc-7985) (Santa Cruz Biotechnology, 1/500), and CD44 (ab51037, Abcam, 1/5000). The blots were then washed, exposed to horseradish peroxidase (HRP)-conjugated secondary antibodies (201-4301 Rockland Immunochemicals, Gilbertsville, PA, USA, 1/5000) for $2 \mathrm{~h}$, and finally detected by ECL chemiluminescence (Thermo Fisher Scientific).

\section{ELISA}

Laminin ELISA kit was purchased from Abnova (Taipei, Taiwan) and HA and human fibronectin ELISA kits were purchased from R\&D Systems. HO-8910 or SKOV-3 cells were treated with or without $10^{-7} \mathrm{~mol} \mathrm{~L}^{-1}$ DEX for the indicated times, and then the conditioned media were collected for ELISA analysis according to the manufacturer's instructions. Absorbance of samples was read at $450 \mathrm{~nm}$ using a UV-visible spectrophotometer. The concentration of protein was calibrated from a dose response curve based on reference standards.

\section{RNA interference}

SiRNAs were manufactured by GenePharma Co, Ltd (Shanghai, China). The sequences were as follows: FN1 siRNA: 5'-GGGACUUCCUAUGUGGUCGGAGAAA-3'; MUC1 siRNA: 5'-CCGAGAAGGUACCAUCAAUTT-3'; and a scramble sequence: 5'-CGCTTACCGATTCAGA ATGG-3' (Agata et al. 2008). Cells were transfected with a final concentration of $10^{-8} \mathrm{~mol} \mathrm{~L}^{-1}$ for FN1 siRNA or $5 \times 10^{-9} \mathrm{~mol} \mathrm{~L}^{-1}$ for MUC1 siRNA using INTERFERin (PolyPlus-Transfection, France) following the manufacturer's instructions.

\section{Cell adhesion assay}

Cell adhesion ability was determined by cell adhesion assay (Chen et al. 2004). Cells were incubated at a proper density into $5 \mathrm{~mL}$ glass flasks and were transfected with FN1 siRNA or MUC1 siRNA for $24 \mathrm{~h}$ and then incubated in the media containing 5\% (v/v) DCC-treated NCS in the presence or absence of $10^{-7} \mathrm{~mol} \mathrm{~L}^{-1} \mathrm{DEX}$ for another $24 \mathrm{~h}$. Then, cells were digested into single cell suspension, and $8 \times 104$ cells were seeded into noncoated 96-well plates and incubated at $37^{\circ} \mathrm{C}$ for $45 \mathrm{~min}$. The plates were gently washed thrice with $1 \times$ PBS to remove the unattached cells. The remaining cells in the 96-well plates were determined by 3-(4,5-dimethylthiazol-2-yl)-2,5-diphenyltetrazolium bromide (MTT) assay.
A

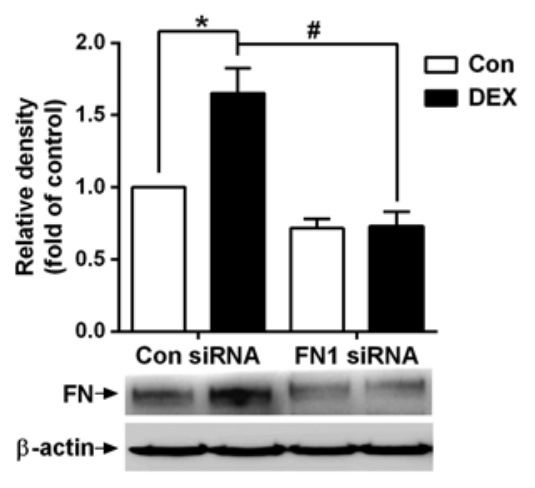

C

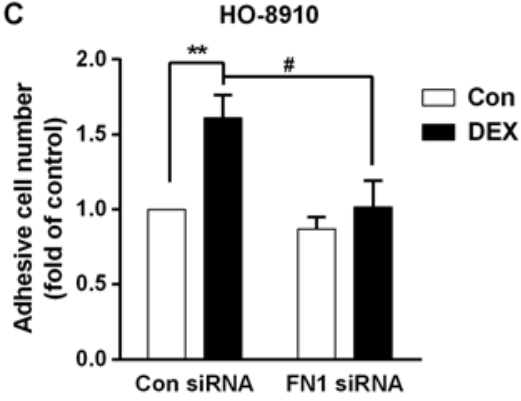

B

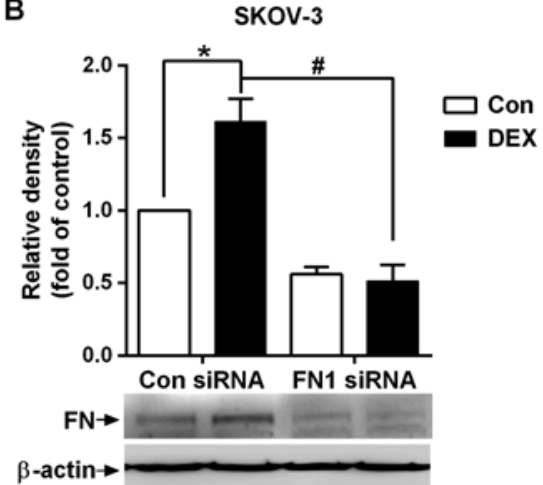

D

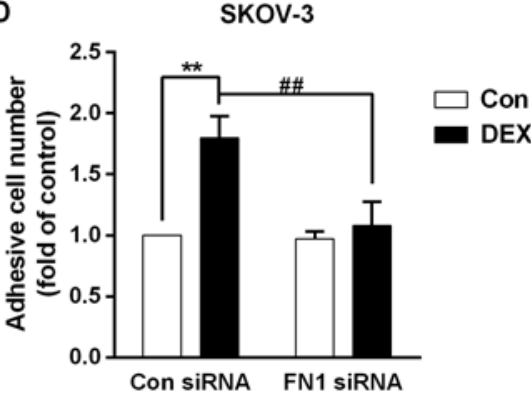

Figure 2

Upregulated expression of FN contributes to the pro-adhesive effect of DEX in ovarian cancer cells. HO-8910 or SKOV-3 cells were transfected with $10^{-8} \mathrm{~mol} \mathrm{~L}^{-1} \mathrm{FN} 1$ siRNA or Con siRNA for $24 \mathrm{~h}$ and then treated with or without $10^{-7} \mathrm{~mol} \mathrm{~L}^{-1}$ DEX for another $24 \mathrm{~h}$. FN knockdown was monitored at the protein level by Western blot and $\beta$-actin was used as a loading control ( $A$ and $B$ ). Single-cell suspension was prepared and $8 \times 104$ cells were seeded into a noncoated 96-well plate. 45 min later, cells were washed thrice with PBS, and the number of the remaining cells attached was determined by MTT assay ( $C$ and D). Data are summarized from three independent sets of experiments. ${ }^{*} P<0.05$, $* * P<0.01$ vs Con siRNA without DEX, $\# P<0.05$, $\# \#<0.01$ vs Con siRNA with DEX. 
Cell adhesion ability was also determined in 96-well plates coated with human fibronectin purchased from Corning (USA) after cells were treated with CD44 primary antibody (103014, Biolegend, San Diego, CA, USA) for 45 min.

\section{Analysis of viability}

Cells were seeded into 96-well culture plates at a density of $2.5 \times 103$ cells per well in triplicate, allowed to attach overnight, and then treated with the indicated factors. Paclitaxel (PTX), a gift from Prof Minghua Zhu (Department of Pathology, Changhai Hospital, the Second Military Medical University), was used to induce cell death. Wortmannin, a PI-3K inhibitor, was purchased from Sigma. At the indicated time, cell viability was evaluated by using Cell Counting Kit-8 (CCK-8, Dojindo Molecular Technologies, Inc, Japan) following the standard procedures provided by manufacturer. The optical density (O.D.) was measured at a wavelength of $450 \mathrm{~nm}$ using a Labsystem multiskan microplate reader (Merck Eurolab, Dietikon, Switzerland).

\section{Statistical analysis}

Data were expressed as mean \pm S.D. of at least three determinations. Statistical significance between experimental groups was analyzed by ANOVA; $P<0.05$ was considered to be statistically significant.

\section{Results}

DEX upregulates the expression of $\mathrm{FN}$, but does not affect the expression of collagens and laminin in ovarian cancer cells

Since our previous study found that DEX promotes cell adhesion to ECM and increases the expression of integrin $\beta 1, \alpha 4$, and $\alpha 5$ in ovarian cancer cells, we first examined the effect of $10^{-7} \mathrm{~mol} \mathrm{~L}^{-1}$ DEX on the expression or secretion of ECM components, the ligands of integrin $\beta 1$. We did not observe significant change in mRNA (data not shown) and protein levels of collagen I, III, IV as well as protein secretion of laminin in HO-8910 cells (Fig. 1A and B). However, we found that $10^{-7} \mathrm{~mol} \mathrm{~L}^{-1}$ DEX upregulated
A

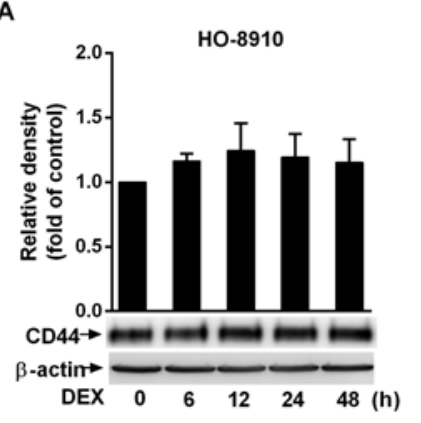

C

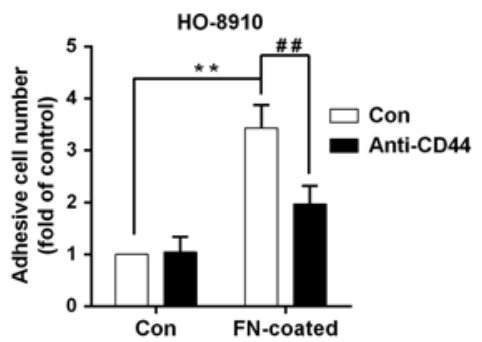

E

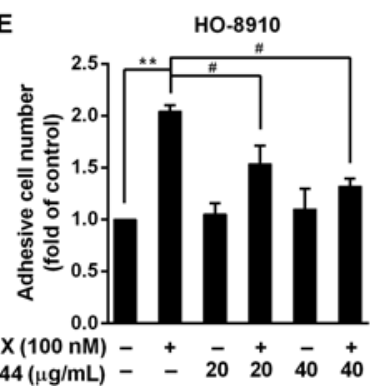

B

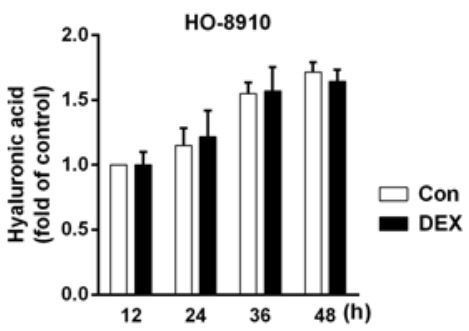

D

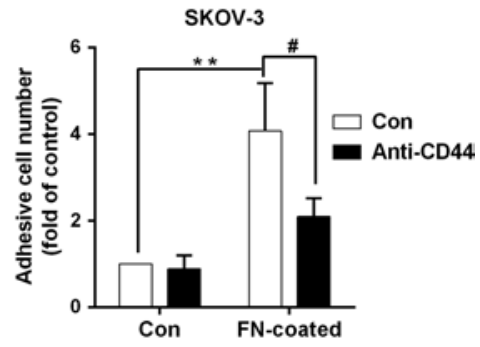

$\mathbf{F}$

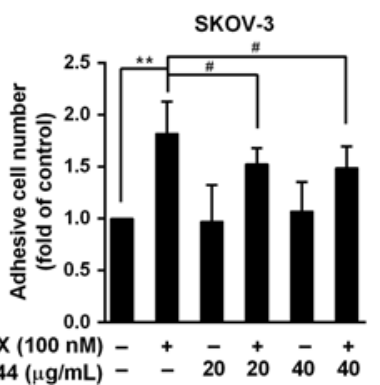

Figure 3

CD44 is involved in the pro-adhesive effect of DEX through interaction with the increased FN. HO-8910 cells were cultured with or without $10^{-7} \mathrm{~mol} \mathrm{~L}^{-1}$ DEX for the indicated times, and the protein level of CD44 (A) and the secreted level of $\mathrm{HA}(\mathrm{B})$ were assessed by Western blot and ELISA, respectively. HO-8910 (C) or SKOV-3 (D) cells were treated with or without $40 \mu \mathrm{g} / \mathrm{mL}$ CD44-blocking antibody for $45 \mathrm{~min}$, and then seeded into 96-well plates coated with or without human fibronectin $(50 \mu \mathrm{g} / \mathrm{mL})$. Cell adhesion was assayed as described in Materials and Methods. ( $E$ and F) Cells were treated with or without $10^{-7} \mathrm{~mol} \mathrm{~L}^{-1}$ DEX for $24 \mathrm{~h}$, and then cultured continuously in the presence or absence of 20 or $40 \mu \mathrm{g} / \mathrm{mL}$ CD44-blocking antibody for another $45 \mathrm{~min}$. Cell adhesion was assayed with noncoated 96-well plates. Data are summarized from three independent sets of experiments. ${ }^{*} P<0.01$ vs control, $\# P<0.05$, $\# \#<0.01$ vs $\mathrm{FN}$-coated ( $C$ and $\mathrm{D}), \# P<0.05$ vs $\operatorname{DEX}(\mathrm{E}$ and $\mathrm{F})$. 
A

D

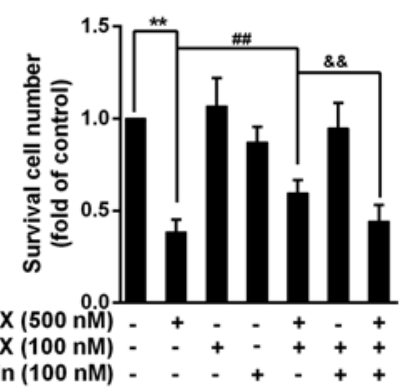

E

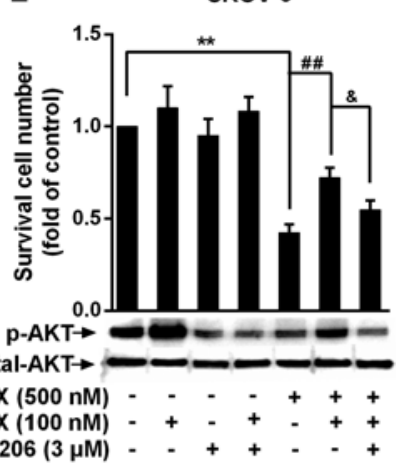

Figure 4

Activation of Akt pathway is involved in pro-survival effect of DEX in ovarian cancer cells. The protein levels of p-AKT and total AKT were assessed in HO-8910 (A) and SKOV-3 (B) cells treated with $10^{-7} \mathrm{~mol} \mathrm{~L}^{-1} \mathrm{DEX}$ for the indicated times. Total AKT was detected as an internal control. The viable cells were analyzed by CCK-8 kit after treatment of HO-8910 (C) and SKOV-3 (D) cells treated with paclitaxel (PTX), DEX, wortmannin, PTX and DEX, DEX and wortmannin, or the combination of PTX, DEX, and wortmannin, for $24 \mathrm{~h}$. Figure $4 \mathrm{E}$ was operated under the same condition besides replacing wortmannin by MK-2206. ${ }^{*} P<0.05$, ${ }^{* *} P<0.01$ vs control, $\# P<0.01$ vs $P T X, \& P<0.05$, \&\&P $<0.01$ vs PTX with DEX. the expression of FN1 mRNA and its protein in a timedependent manner, with the maximal induction of mRNA (1.7-fold of control, $P<0.05)$ at $24 \mathrm{~h}$ and protein (4.2-fold of control, $P<0.01$ ) at $48 \mathrm{~h}$ after DEX treatment in HO-8910 cells (Fig. 1C and D). The increases in intracellular and secreted levels of FN were also observed in SKOV-3 cells (Fig. 1E and F). The level of FN protein induced by DEX was much higher than that of FN1 mRNA, suggesting that DEX upregulated the expression of FN mainly through translation or post-translation mechanism.

\section{Upregulated expression of FN contributes to the pro-adhesive effect of DEX in ovarian cancer cells}

As a multifunctional extracellular matrix glycoprotein and a core component of many extracellular matrices, FN plays an important role in promoting cell adhesion, migration, and signal transduction (Leiss et al. 2008, Schiller et al. 2013, Masamha et al. 2014). We, therefore, investigated whether the upregulation of FN expression by DEX was related to the pro-adhesive effect of DEX using specific small RNA interference (FN1 siRNA). Western blot showed that knockdown of FN1 with FN1 siRNA almost abolished the DEX-induced expression of FN1 in HO-8910 and SKOV-3cells (Fig. 2A and B). As shown in Fig. 2C and $\mathrm{D}, 10^{-7} \mathrm{~mol} \mathrm{~L}^{-1} \mathrm{DEX}$ significantly enhanced the adhesion ability of HO-8910 and SKOV-3 cells transfected with control siRNA. However, the pro-adhesive effect of DEX in FN1 knockdown cells was almost completely inhibited. These results indicated that upregulation of FN mediates the pro-adhesive effect of DEX in ovarian cancer cells.

\section{CD44 is involved in the pro-adhesive effect of DEX through interaction with the increased FN}

CD44 is a broadly distributed transmembrane glycoprotein that mediates cell-matrix interactions through binding to its principal ligand, HA, as well as

Published by Bioscientifica Ltd 
other components of ECM, such as FN and collagens and laminin (Naor et al. 1997, Ponta et al. 2003). We first examined the effects of DEX on CD44 at protein level by western blotting analysis and the secretion of HA by ELISA assay, respectively, and found that neither CD44 nor HA was significantly altered in HO-8910 cells after treatment with DEX for $48 \mathrm{~h}$ (Fig. $3 \mathrm{~A}$ and B). Since DEX upregulated the expression of FN, which is also the ligand of CD44, we proposed that CD44 might be involved in the pro-adhesive effect of DEX through interaction with the increased FN. In order to determine this hypothesis, we treated cells with or without $40 \mu \mathrm{g} / \mathrm{mL}$ CD44-blocking antibody for $45 \mathrm{~min}$, and then cultured cells on noncoated or FN-coated 96-well plates (to imitate the FN overexpression) to determine cell adhesion ability. The result showed that the number of adhering cells in the FN-coated group markedly increased by 3.4fold compared with that in the noncoated control group. However, FN-enhancement of cell adhesion was reduced to 1.9-fold in HO-8910 cells treated with CD44-blocking antibody $(P<0.01$, Fig. 3C). Similar results were also observed in SKOV-3 cells (from 4.1 to 2.1 -fold, $P<0.05$, Fig. 3D), indicating that CD44 partially mediates FN-enhanced cell adhesion. Further experiments showed that DEX significantly enhanced cell adhesion in noncoated plates (about two-fold of that in control cells,
$P<0.01)$. However, $40 \mu \mathrm{g} / \mathrm{mL}$ CD44-blocking antibody reduced DEX-enhanced cell adhesion by $69.3 \%(P<0.05$ vs DEX, Fig. 3E). Similar results were also observed in SKOV-3 cells (Fig. 3F). These results supported that besides integrin $\beta 1, \mathrm{CD} 44$ is also involved in the proadhesive effect of DEX partially through binding to the increased FN.

\section{Activation of Akt pathway is involved in pro-survival effect of DEX in ovarian cancer cells}

It is known that $\mathrm{FN}$ is the ligand of integrin $\beta 1$ and $\mathrm{CD} 44$. The interaction of FN-integrin $\beta 1$ or FN-CD44 mediates the cell adhesion, and induces signaling, such as activating PI-3K-Akt pathway (Schmidt \& Friedl 2010, Nakagawa et al. 2014, Li et al. 2015, Onodera et al. 2015, McFarlane et al. 2015), which is an important pathway to promote cell survival (Benbrook \& Masamha 2011). We then examined whether PI-3K-Akt pathway was involved in the prosurvival effect of DEX in ovarian cancer cells. The results showed that $10^{-7} \mathrm{~mol} \mathrm{~L}^{-1}$ DEX significantly enhanced the level of phosphorylated Akt at $12 \mathrm{~h}$ in HO-8910 cells (1.9-fold of control, $P<0.05$ ) and at $24 \mathrm{~h}$ in SKOV-3 cells (2.6-fold of control, $P<0.01$ ) after DEX treatment, and the increased phosphorylation of AKT sustained for at least $36 \mathrm{~h}$ after DEX treatment (Fig. 4A and B), indicating that
A

HO-8910

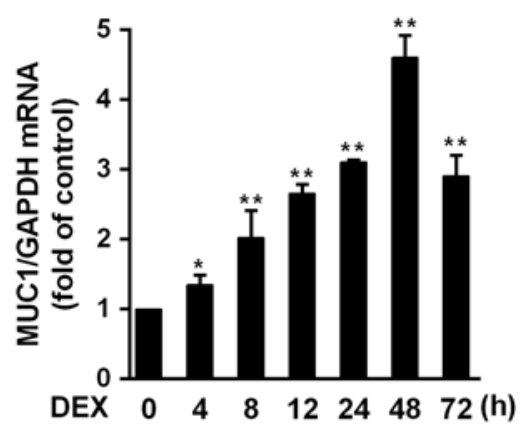

C

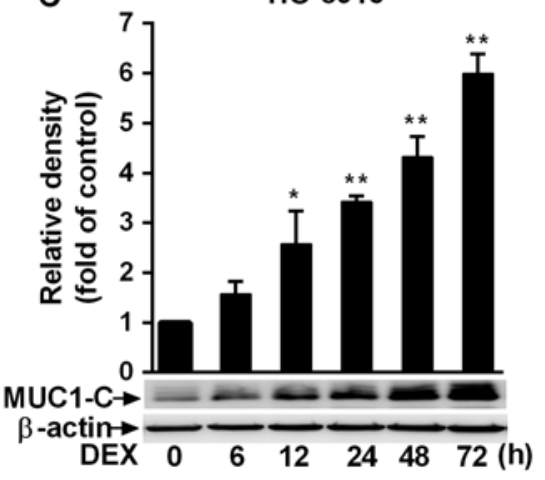

B

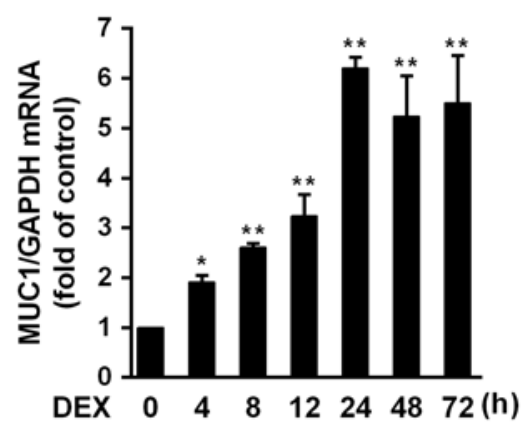

D

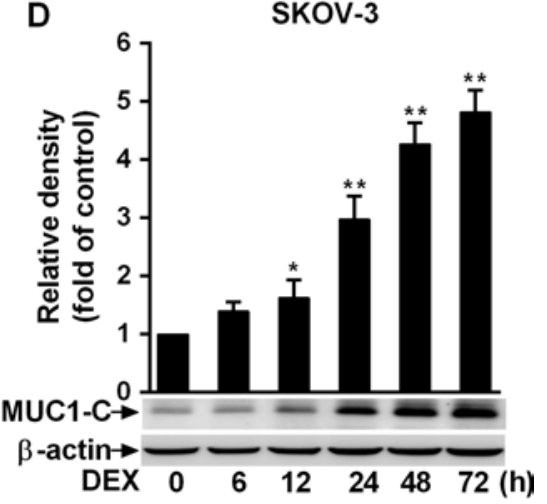

Figure 5

DEX upregulates the expression of MUC1 in ovarian cancer cells. HO-8910 (A and C) and SKOV-3 ( $B$ and $D)$ cells were treated with $10^{-7} \mathrm{~mol} \mathrm{~L}^{-1} \mathrm{DEX}$ for the indicated times, and the levels of MUC1 mRNA and protein were assessed by real-time PCR and western blot analysis using GAPDH or $\beta$-actin as normalization controls, respectively. The results were expressed as fold over control and represented at least three independent experiments. ${ }^{*} P<0.05$, $* * P<0.01$ vs 0 . http://jme.endocrinology-journals.org
DOI: 10.1530/JME-15-0142
(C) 2016 Society for Endocrinology Printed in Great Britain
Published by Bioscientifica Ltd 
A
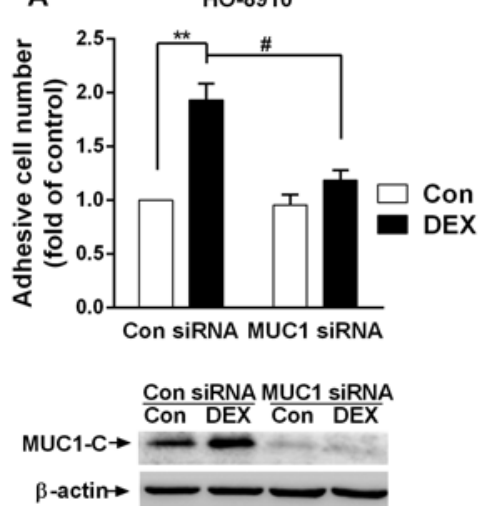

B SKOV-3
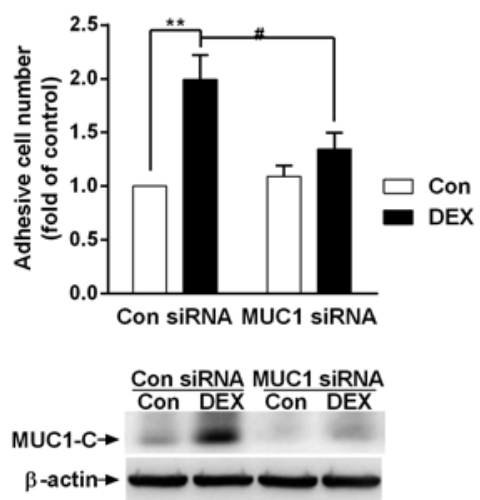

C

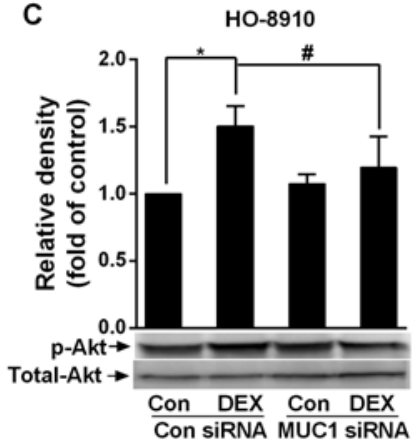

D

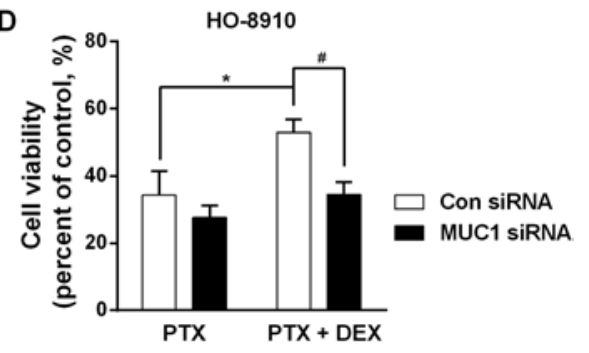

E

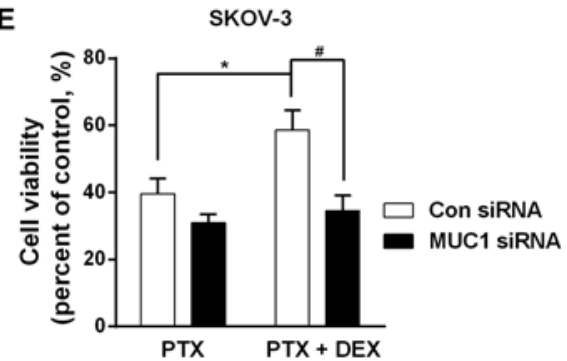

Figure 6

MUC1 partially mediates DEX-induced pro-adhesion, AKT activation, and enhancement of chemotherapeutic resistance in ovarian cancer cells. HO-8910 (A) or SKOV-3 (B) cells were transfected with $5 \times 10^{-9} \mathrm{~mol} \mathrm{~L}^{-1} \mathrm{MUC} 1$ siRNA or Con siRNA for $24 \mathrm{~h}$ and then cultured with or without $10^{-7} \mathrm{~mol} \mathrm{~L}^{-1}$ DEX for another $24 \mathrm{~h}$ followed by cell adhesion assessment. Knockdown of MUC1 was confirmed by Western blot. The protein levels of p-AKT and total AKT in HO-8910 cells in each group were examined by western blot, and total AKT was used as a normalization control (C). HO-8910 (D) or SKOV-3 (E) cells were seeded in 96-well culture plates in triplicate and were transfected with $5 \times 10^{-9} \mathrm{~mol}$ $\mathrm{L}^{-1}$ MUC1 SiRNA or Con siRNA for 24h. Cells were pretreated with or without $10^{-7} \mathrm{~mol} \mathrm{~L}^{-1} \mathrm{DEX}$ for $24 \mathrm{~h}$, and then cultured continuously in the presence or absence of $5 \times 10^{-7} \mathrm{~mol} \mathrm{~L}^{-1}$ PTX for another $48 \mathrm{~h}$. Cell survival was analyzed by CCK- 8 kit. Data are summarized from three independent sets of experiments. ${ }^{*} P<0.05$, $* * P<0.01$ vs Con siRNA, or Con siRNA combined with PTX. $\# P<0.05$ vs Con siRNA combined with PTX and DEX. the activation of Akt by DEX is a late phase and sustained regulation. DEX also increased cell resistance to the chemotherapeutic agent paclitaxel (PTX). As shown in Fig. 4C, after treatment of cells with both $5 \times 10^{-7} \mathrm{~mol} \mathrm{~L}^{-1}$ PTX and $10^{-7} \mathrm{~mol} \mathrm{~L}^{-1}$ DEX for $24 \mathrm{~h}$, the viable cell number was increased from 38.7 to $59.3 \%$ compared with that in cells treated with PTX alone $(P<0.01)$. Inhibiting activity of Akt in HO-8910 cell with $10^{-7} \mathrm{~mol} \mathrm{~L}^{-1}$ wortmannin, a PI-3K inhibitor, could significantly reduce the DEXinduced increase in viable cell number in HO-8910 cells (from 59.3 to $44.3 \%, P<0.01$ ). Similar results were also observed in SKOV-3 cells (Fig. 4D). We further detected the relationship between Akt activation and cell viability in SKOV-3 cells with more specific Akt inhibitor, MK-2206. The result showed that the basal cell viability was not significantly affected by Akt activity. DEX significantly increased viable cell number and level of p-AKT in the presence of PTX. Inhibiting Akt activation with MK-2206 partially blocked the protective effect of DEX (Fig. 4E). These results indicated that activation of the PI-3K-Akt pathway was involved in the DEX-induced pro-survival effect and the enhancement of PTX resistance in ovarian cancer cells.

\section{DEX upregulates the expression of MUC1 in ovarian cancer cells}

MUC1 is a large transmembrane epithelial mucin glycoprotein that impacts cell proliferation, survival, and invasion (Senapati et al. 2010, Ahmad et al. 2011, Li et al. 2011, Raina et al. 2011). However, it is unclear whether MUC1 participates in the effect of DEX on tumor biology. We therefore examined the effect of DEX on the expression of MUC1 in HO-8910 and SKOV-3 cells and found that $10^{-7} \mathrm{~mol} \mathrm{~L}-1$ DEX significantly increased MUC1 expression at both mRNA and protein levels in a time-dependent manner. MUC1 protein induced by DEX at $72 \mathrm{~h}$ was 6.0 -fold of that in control $(P<0.01)$ in HO-8910 cells, and 4.8 -fold of that in control $(P<0.01)$ in SKOV-3 cells, respectively (Fig. 5C and D). Increased protein level of MUC1 by DEX lasted at least $72 \mathrm{~h}$, whereas its mRNA level was decreased at $72 \mathrm{~h}$, suggesting that DEX

Published by Bioscientifica Ltd 
upregulates the expression of MUC1 at least through transcription and posttranslation mechanisms.

\section{MUC1 partially mediates DEX-induced pro-adhesion, Akt activation, and enhancement of chemotherapeutic resistance in ovarian cancer cells}

Since DEX induced the expression of MUC1, we further investigated whether MUC1 was involved in DEX effects of pro-adhesion, Akt activation, and pro-survival in ovarian cancer cells using specific small RNA interference (MUC1 siRNA). As shown in Fig. 6A and B, inhibition of the expression of MUC1 alone did not affect cell adhesion in the absence of DEX, but significantly attenuated the proadhesive effect of DEX (from 1.9- to 1.2-fold in HO-8910 cells and from 2.0- to 1.3-fold in SKOV-3 cells, respectively. $P<0.05)$. Moreover, DEX-induced increase in p-AKT was also significantly reduced in MUC1-knockdown SKOV-3 cells (Fig. 6C). Finally, it was found that $10^{-7} \mathrm{~mol} \mathrm{~L}^{-1}$ DEX significantly increased the survival of cells transfected with control siRNA in the presence of $5 \times 10^{-7} \mathrm{~mol} \mathrm{~L}^{-1}$ PTX from 34.3 to $53.0 \%$ in HO-8910 and from 39.6 to $58.6 \%$ in SKOV-3 cells $(P<0.05)$, respectively. By contrast, inhibiting the expression of MUC1 by specific siRNA almost abolished the pro-survival effect of DEX (Fig. 6D and E). These results indicated that the upregulation of MUC1 by DEX is involved in DEX-induced pro-adhesion, Akt activation, and enhancement of chemotherapeutic resistance in ovarian cancer cells.

\section{Discussion}

In our previous report, we found that DEX significantly increases cell adhesion to ECM by increasing levels of integrins $\beta 1, \alpha 4$, and $\alpha 5$ (Chen et al. 2010). Integrin $\beta 1$ comprises a family of heterodimeric ECM receptors that interact with components of ECM, such as collagens, FN, and laminin (Cukierman \& Bassi 2012). Therefore, in the present study, we further investigated the influence of DEX on the expression of components of ECM. The results demonstrated that DEX did not change the expression of collagen I, III, IV, and laminin, but significantly increased the expression of FN in ovarian cancer cells, including its secreted form. Increase in synthesis of FN and induction of FN matrix assembly by GC have been reported previously in normal human fibroblasts, HT1080 fibrosarcoma cells (Oliver et al. 1983, McKeown-Longo \& Etzler 1987) and chick hepatocytes (Nimmer et al. 1987). However, it was also reported that GC negatively regulates the expression of FN in placenta (Guller et al. 1994). Therefore, it seems that the regulation of FN expression by GC is dependent on cell type. In this study, it was found that DEX significantly increased both intracellular and secreted levels of FN in ovarian cancer cells. In addition, knockdown of FN expression significantly decreased the pro-adhesive effect of DEX. These results indicated that FN1 mediates the pro-adhesive effect of DEX in ovarian cancer cells.

CD44, a broadly distributed transmembrane glycoprotein, mediates cell-matrix interactions through binding to its principal ligand $\mathrm{HA}$ as well as other components of ECM, such as FN, collagens, and laminin (Cichy \& Pure 2003, Ponta et al. 2003). Since our previous study showed that blocking integrin $\beta 1$ with its antibody only partially blocks the pro-adhesive effect of DEX (Chen et al. 2010), we wondered if other adhesive molecules besides integrin $\beta 1$ also mediate the pro-adhesive effect of DEX. We investigated the possible role of CD44 in DEX-enhanced cell adhesion. Although the expression of CD44 and its principal ligand HA was not regulated by DEX, blocking CD44 with a specific antibody significantly attenuated both FN-enhanced cell adhesion and DEX-induced cell adhesion in ovarian cancer cells. These results indicated that besides integrin $\beta 1$, interaction between FN and CD44 also contributes to the pro-adhesive effect of DEX.

FN is a multifunctional extracellular matrix glycoprotein and a core component of many extracellular matrices. It is known that increased adhesion by $\mathrm{FN}$-integrin $\beta 1$ interaction plays an essential role in regulating cell proliferation, survival, and migration by triggering several signaling pathways (Leiss et al. 2008, Schmidt \& Friedl 2010, Schiller et al. 2013, Nakagawa et al. 2014), especially PI-3K-Akt pathway, which is the most important pathway to promote cell survival (Benbrook \& Masamha 2011). Interaction of CD44 with its ligands, including $\mathrm{FN}$, can also enhance proliferation, survival, and invasion by activating PI-3K-Akt pathways (Li et al. 2015, McFarlane et al. 2015, Onodera et al. 2015). In this study, we demonstrated that DEX could enhance the activation of Akt, which is a late phase and sustained regulation, suggesting that Akt activation is not a direct effect of DEX, but the result of DEXenhanced cell adhesion. Further experiment showed that activation of PI-3K-Akt pathway by DEX was involved in the pro-survival effects and enhancement of PTX resistance in ovarian cancer cells.

MUC1, a heterodimeric transmembrane glycoprotein composed of $\alpha$ and $\beta$ subunits, is expressed in most epithelial cells. In tumor cells, MUC1 is aberrantly highly expressed, underglycosylated, and no longer restricted to the apical side of the cell (Kufe 2009, Van Elssen et al. 2010, Albrecht \& Carraway 2011). These changes facilitate

Published by Bioscientifica Ltd 
the interaction between MUC1 $\alpha$ and extracellular matrix components and trigger multiple cancer-related signaling pathways, thereby promoting cell invasion and enhancing cell resistance to genotoxic anticancer reagents in cancer cells including ovarian cancer cells (Kufe 2009, Hisatsune et al. 2011). Although DEX has been shown to upregulate human MUC1 expression in several kinds of cells (Treon et al. 1999, Imai et al. 2004, Seo et al. 2007, Agata et al. 2008), it is unclear whether MUC1 is involved in the effect of DEX on cell adhesion and survival. Here, we demonstrated that DEX significantly induced the expression of MUC1 in ovarian cancer cells. Knockdown of MUC1 significantly attenuated the DEX-induced effects of pro-adhesion, Akt activation, and enhancement of cell resistance to PTX, indicating that the upregulation of MUC1 by DEX was involved in pro-adhesion and prosurvival effects of DEX in human ovarian cancer cells.

In this study, we demonstrated that DEX upregulated FN1 and MUC1, and knockdown of either FN1 or MUC1 markedly suppressed DEX-enhanced cell adhesion. It is unclear how FN and MUC1 pathways contribute to DEXenhanced cell adhesion. It has been reported that MUC1 is a downstream target of STAT3 (Gao et al. 2009), and that binding of FN to integrin $\beta 1$ can activate STAT3, resulting in the upregulation of MUC1 in human breast cancer cells (Li et al. 2014). Liao and coworkers reported that MUC1 overexpression induced by IGF1 precedes the changes in FN expression. IGF1 induces the upregulation of $\mathrm{FN}$ in a MUC1-dependent manner in MCF-7 cells (Liao et al. 2014). Further study is required to clarify the relationship between MUC1 and FN in DEX-enhanced cell adhesion.

In summary, this study provides new data that DEX promotes cell adhesion through upregulation of FN and MUC1, thereby enhancing cell resistance to chemotherapy by activating PI-3K-Akt pathway in ovarian cancer cells.

\section{Declaration of interest}

The authors declare that there is no conflict of interest that could be perceived as prejudicing the impartiality of the research reported.

\section{Funding}

This work was supported by grant from National Natural Science Foundation of China (No. 81472690 and 91029722).

\section{Author contribution statement}

$J \mathrm{~L}$ and $\mathrm{N} \mathrm{H}$ supervised the project and designed the experiments. $\mathrm{L} Y$ and F F designed and performed most of the experiments. X S and G $\mathrm{H}$ did part of experiment. J $S$ and $Y W$ provided technical assistance in the study. $L Y$,
F F, J L, and $\mathrm{N} \mathrm{H}$ analyzed the data. $J \mathrm{~L}$ and $\mathrm{L} Y$ wrote the paper. All authors approved the paper for the submission.

\section{Acknowledgment}

The authors thank Dr Liangnian Song (Herbert Irving Comprehensive Cancer Center Columbia University, USA) who helped us in English editing in this manuscript.

\section{References}

Agata N, Ahmad R, Kawano T, Raina D, Kharbanda S \& Kufe D 2008 MUC1 oncoprotein blocks death receptor-mediated apoptosis by inhibiting recruitment of caspase-8. Cancer Research 68 6136-6144. (doi:10.1158/0008-5472.CAN-08-0464)

Ahmad R, Rajabi H, Kosugi M, Joshi MD, Alam M, Vasir B, Kawano T, Kharbanda S \& Kufe D 2011 MUC1-C oncoprotein promotes STAT3 activation in an autoinductive regulatory loop. Science Signaling 4 ra9. (doi:10.1126/scisignal.2001426)

Albrecht H \& Carraway KL 2011 MUC1 and MUC4: switching the emphasis from large to small. Cancer Biotherapy and Radiopharmaceuticals 26 261-271. (doi:10.1089/cbr.2011.1017)

Baschant U \& Tuckermann J 2010 The role of the glucocorticoid receptor in inflammation and immunity. Journal of Steroid Biochemistry and Molecular Biology 120 69-75. (doi:10.1016/ j.jsbmb.2010.03.058)

Beck IM, Vanden Berghe W, Vermeulen L, Yamamoto KR, Haegeman G \& De Bosscher K 2009 Crosstalk in inflammation: the interplay of glucocorticoid receptor-based mechanisms and kinases and phosphatases. Endocrine Reviews 30 830-882. (doi:10.1210/er.2009-0013)

Benbrook DM \& Masamha CP 2011 The pro-survival function of Akt kinase can be overridden or altered to contribute to induction of apoptosis. Current Cancer Drug Targets 11 586-599. (doi:10.2174/1568 $00911795655994)$

Chen BQ, Yang YM, Wang Q, Gao YH, Liu JR, Zhang JS, Wang XL \& Liu RH 2004 Effects of c9,t11-conjugated linoleic acid on adhesion of human gastric carcinoma cell line SGC-7901. World Journal of Gastroenterology 10 1392-1396. (doi:10.3748/wjg.v10.i10.1392)

Chen YX, Wang Y, Fu CC, Diao F, Song LN, Li ZB, Yang R \& Lu J 2010 Dexamethasone enhances cell resistance to chemotherapy by increasing adhesion to extracellular matrix in human ovarian cancer cells. Endocrine-Related Cancer 17 39-50. (doi:10.1677/ERC-08-0296)

Cichy J \& Pure E 2003 The liberation of CD44. Journal of Cell Biology 161 839-843. (doi:10.1083/jcb.200302098)

Cukierman E \& Bassi DE 2012 The mesenchymal tumor microenvironment: a drug-resistant niche. Cell Adhesion \& Migration 6 285-296. (doi:10.4161/cam.20210)

Gao J, McConnell MJ, Yu B, Li J, Balko JM, Black EP, Johnson JO, Lloyd MC, Altiok S \& Haura EB 2009 MUC1 is a downstream target of STAT3 and regulates lung cancer cell survival and invasion. International Journal of Oncology 35 337-345. (doi:10.3892/ ijo_00000345)

Guller S, Wozniak R, Leibman MI \& Lockwood CJ 1994 Negative regulation of placental fibronectin expression by glucocorticoids and cyclic adenosine 3',5'-monophosphate. Annals of the New York Academy of Sciences 734 132-142. (doi:10.1111/j.1749-6632.1994. tb21741.x)

Herr I, Ucur E, Herzer K, Okouoyo S, Ridder R, Krammer PH, Doeberitz MV \& Debatin KM 2003 Glucocorticoid cotreatment induces apoptosis resistance toward cancer therapy in carcinomas. Cancer Research 63 3112-3120.

Herr I, Gassler N, Friess H \& Buchler MW 2007 Regulation of differential pro- and anti-apoptotic signaling by glucocorticoids. Apoptosis $\mathbf{1 2}$ 271-291. (doi:10.1007/s10495-006-0624-5)

Published by Bioscientifica Ltd. 
Hisatsune A, Nakayama H, Kawasaki M, Horie I, Miyata T, Isohama Y, Kim KC \& Katsuki H 2011 Anti-MUC1 antibody inhibits EGF receptor signaling in cancer cells. Biochemical and Biophysical Research Communications 405 377-381. (doi:10.1016/j.bbrc.2011.01.029)

Hynes RO 2002 Integrins: bidirectional, allosteric signaling machines. Cell 110 673-687. (doi:10.1016/S0092-8674(02)00971-6)

Imai M, Hwang HY, Norris JS \& Tomlinson S 2004 The effect of dexamethasone on human mucin 1 expression and antibodydependent complement sensitivity in a prostate cancer cell line in vitro and in vivo. Immunology $111291-297$. (doi:10.1111/j.0019-2805.2004.01815.x)

Kassel O \& Herrlich P 2007 Crosstalk between the glucocorticoid receptor and other transcription factors: molecular aspects. Molecular and Cellular Endocrinology 275 13-29. (doi:10.1016/j.mce.2007.07.003)

Kriegler AB, Bernardo D \& Verschoor SM 1994 Protection of murine bone marrow by dexamethasone during cytotoxic chemotherapy. Blood 83 65-71.

Kufe DW 2009 Functional targeting of the MUC1 oncogene in human cancers. Cancer Biology \& Therapy 8 1197-1203.

Kyriakis JM, Banerjee P, Nikolakaki E, Dai T, Rubie EA, Ahmad MF, Avruch J \& Woodgett JR 1994 The stress-activated protein kinase subfamily of c-Jun kinases. Nature 369 156-160. (doi:10.1038/369156a0)

Leiss M, Beckmann K, Giros A, Costell M \& Fassler R 2008 The role of integrin binding sites in fibronectin matrix assembly in vivo. Current Opinion in Cell Biology 20 502-507. (doi:10.1016/j.ceb.2008.06.001)

Li Y, Yi HY, Yao YX, Liao XD, Xie YQ, Yang J, Yan Z, Wang L, Lu SY, Kuang Y, et al. 2011 The cytoplasmic domain of MUC1 induces hyperplasia in the mammary gland and correlates with nuclear accumulation of beta-catenin. PLOS ONE 6 e19102. (doi:10.1371/ journal.pone.0019102)

Li G, Zhao L, Li W, Fan K, Qian W, Hou S, Wang H, Dai J, Wei H \& Guo Y 2014 Feedback activation of STAT3 mediates trastuzumab resistance via upregulation of MUC1 and MUC4 expression. Oncotarget 5 8317-8329. (doi:10.18632/oncotarget)

Li XP, Zhang XW, Zheng LZ \& Guo WJ 2015 Expression of CD44 in pancreatic cancer and its significance. International Journal of Clinical and Experimental Pathology 8 6724-6731.

Liao G, Wang M, Ou Y \& Zhao Y 2014 IGF-1-induced epithelialmesenchymal transition in MCF-7 cells is mediated by MUC1. Cell Signaling 26 2131-2137. (doi:10.1016/j.cellsig.2014.06.004)

Masamha CP, Xia Z, Yang J, Albrecht TR, Li M, Shyu AB, Li W \& Wagner EJ 2014 CFIm25 links alternative polyadenylation to glioblastoma tumour suppression. Nature 510 412-416. (doi:10.1038/nature13261)

McFarlane S, McFarlane C, Montgomery N, Hill A \& Waugh DJ 2015 CD44-mediated activation of alpha5beta1-integrin, cortactin and paxillin signaling underpins adhesion of basal-like breast cancer cells to endothelium and fibronectin-enriched matrices. Oncotarget 6 36762-36773. (doi:10.18632/oncotarget.5461)

McKeown-Longo PJ \& Etzler CA 1987 Induction of fibronectin matrix assembly in human fibrosarcoma cells by dexamethasone. Journal of Cell Biology 104 601-610. (doi:10.1083/jcb.104.3.601)

Mou HZ, Xu SH \& Zhang YY 1994 [The establishment of human ovarian carcinoma cell line HO-8910 and its characteristics]. Zhonghua Fu Chan Ke Za Zhi 29 162-164, 191.

Nakagawa Y, Nakayama H, Nagata M, Yoshida R, Kawahara K, Hirosue A, Tanaka T, Yuno A, Matsuoka Y, Kojima T, et al. 2014 Overexpression of fibronectin confers cell adhesion-mediated drug resistance (CAM-DR) against 5-FU in oral squamous cell carcinoma cells. International Journal of Oncology 44 1376-1384. (doi:10.3892/ijo.2014.2265)

Naor D, Sionov RV \& Ish-Shalom D 1997 CD44: structure, function, and association with the malignant process. Advances in Cancer Research 71 241-319. (doi:10.1016/S0065-230X(08)60101-3)

Nimmer D, Bergtrom G, Hirano H \& Amrani DL 1987 Regulation of plasma fibronectin biosynthesis by glucocorticoids in chick hepatocyte cultures. Journal of Biological Chemistry 262 10369-10375.

http://jme.endocrinology-journals.org

DOI: 10.1530/JME-15-0142 (c) 2016 Society for Endocrinology Printed in Great Britain
Oliver N, Newby RF, Furcht LT \& Bourgeois S 1983 Regulation of fibronectin biosynthesis by glucocorticoids in human fibrosarcoma cells and normal fibroblasts. Cell 33 287-296. (doi:10.1016/00928674(83)90357-4)

Onodera Y, Teramura T, Takehara T \& Fukuda K 2015 Hyaluronic acid regulates a key redox control factor Nrf2 via phosphorylation of Akt in bovine articular chondrocytes. FEBS Open Biology 5 476-484. (doi:10.1016/j.fob.2015.05.007)

Paul A, Wilson S, Belham CM, Robinson CJ, Scott PH, Gould GW \& Plevin R 1997 Stress-activated protein kinases: activation, regulation and function. Cell Signaling 9 403-410. (doi:10.1016/S08986568(97)00042-9)

Phuc Le P, Friedman JR, Schug J, Brestelli JE, Parker JB, Bochkis IM \& Kaestner KH 2005 Glucocorticoid receptor-dependent gene regulatory networks. PLoS Genetics 1 e16. (doi:10.1371/journal. pgen.0010016)

Ponta H, Sherman L \& Herrlich PA 2003 CD44: from adhesion molecules to signalling regulators. Nature Reviews Molecular Cell Biology 4 33-45. (doi:10.1038/nrm1004)

Price MA, Cruzalegui FH \& Treisman R 1996 The p38 and ERK MAP kinase pathways cooperate to activate Ternary Complex Factors and c-fos transcription in response to UV light. EMBO Journal 15 6552-6563.

Raina D, Kosugi M, Ahmad R, Panchamoorthy G, Rajabi H, Alam M, Shimamura T, Shapiro GI, Supko J, Kharbanda S, et al. 2011 Dependence on the MUC1-C oncoprotein in non-small cell lung cancer cells. Molecular Cancer Therapeutics 10 806-816. (doi:10.1158/1535-7163.MCT-10-1050)

Rutz HP 2002 Effects of corticosteroid use on treatment of solid tumours. Lancet 360 1969-1970. (doi:10.1016/S0140-6736(02)11922-2)

Rutz HP \& Herr I 2004 Interference of glucocorticoids with apoptosis signaling and host-tumor interactions. Cancer Biology \& Therapy $\mathbf{3}$ $715-718$.

Schiller HB, Hermann MR, Polleux J, Vignaud T, Zanivan S, Friedel CC, Sun ZQ, Raducanu A, Gottschalk KE, Thery M, et al. 2013 beta(1)and alpha(v)-class integrins cooperate to regulate myosin II during rigidity sensing of fibronectin-based microenvironments. Nature Cell Biology 15 625-636. (doi:10.1038/ncb2747)

Schmalzing G, Richter HP, Hansen A, Schwarz W, Just I \& Aktories K 1995 Involvement of the GTP binding protein Rho in constitutive endocytosis in Xenopus laevis oocytes. Journal of Cell Biology 130 1319-1332. (doi:10.1083/jcb.130.6.1319)

Schmidt S \& Friedl P 2010 Interstitial cell migration: integrin-dependent and alternative adhesion mechanisms. Cell and Tissue Research 339 83-92. (doi:10.1007/s00441-009-0892-9)

Senapati S, Das S \& Batra SK 2010 Mucin-interacting proteins: from function to therapeutics. Trends in Biochemical Sciences 35 236-245. (doi:10.1016/j.tibs.2009.10.003)

Seo KY, Chung SH, Lee JH, Park MY \& Kim EK 2007 Regulation of membrane-associated mucins in the human corneal epithelial cells by dexamethasone. Cornea 26 709-714. (doi:10.1097/ ICO.0b013e31804f5a09)

Sui M, Chen F, Chen Z \& Fan W 2006 Glucocorticoids interfere with therapeutic efficacy of paclitaxel against human breast and ovarian xenograft tumors. International Journal of Cancer 119 712-717. (doi:10.1002/ijc.21743)

Treon SP, Mollick JA, Urashima M, Teoh G, Chauhan D, Ogata A, Raje N, Hilgers JHM, Nadler L, Belch AR, et al. 1999 Muc-1 core protein is expressed on multiple myeloma cells and is induced by dexamethasone. Blood 93 1287-1298.

Van Elssen CHMJ, Frings PWH, Bot FJ, Van de Vijver KK, Huls MB, Meek B, Hupperets P, Germeraad WTV \& Bos GMJ 2010 Expression of aberrantly glycosylated Mucin-1 in ovarian cancer. Histopathology 57 597-606. (doi:10.1111/j.1365-2559.2010.03667.x)

Warny M, Keates AC, Keates S, Castagliuolo I, Zacks JK, Aboudola S, Qamar A, Pothoulakis C, LaMont JT \& Kelly CP 2000 p38 MAP kinase activation by Clostridium difficile toxin A mediates monocyte 
necrosis, IL-8 production, and enteritis. Journal of Clinical Investigation 105 1147-1156. (doi:10.1172/JCI7545)

Winograd-Katz SE, Fassler R, Geiger B \& Legate KR 2014 The integrin adhesome: from genes and proteins to human disease. Nature Reviews Molecular Cell Biology 15 273-288. (doi:10.1038/ nrm3769)

Zaidel-Bar R \& Geiger B 2010 The switchable integrin adhesome. Journal of Cell Science 123 1385-1388. (doi:10.1242/jcs.066183)

Zaidel-Bar R, Itzkovitz S, Ma'ayan A, Iyengar R \& Geiger B 2007 Functional atlas of the integrin adhesome. Nature Cell Biology 9 858-868. (doi:10.1038/ncb0807-858)
Zhang C, Beckermann B, Kallifatidis G, Liu Z, Rittgen W, Edler L, Buchler P, Debatin KM, Buchler MW, Friess H, et al. $2006 a$ Corticosteroids induce chemotherapy resistance in the majority of tumour cells from bone, brain, breast, cervix, melanoma and neuroblastoma. International Journal of Oncology 29 1295-1301. (doi:10.3892/ijo.29.5.1295)

Zhang C, Marme A, Wenger T, Gutwein P, Edler L, Rittgen W, Debatin KM, Altevogt P, Mattern J \& Herr I 2006b Glucocorticoidmediated inhibition of chemotherapy in ovarian carcinomas. International Journal of Oncology 28 551-558. (doi:10.3892/ ijo.28.2.551)

Received in final form 24 April 2016

Accepted 4 May 2016

Accepted Preprint published online 5 May 2016 (c) 2016 Society for Endocrinology Printed in Great Britain
Published by Bioscientifica Ltd. 